Psychological Medicine

cambridge.org/psm

\section{Correspondence}

\section{Letter to the Editor}

Cite this article: Jonsson $\mathrm{BH}$, Winzer $\mathrm{R}$, Gornitzki C (2018). Are older studies lost in database searches for systematic reviews? Psychological Medicine 48, 1218-1219. https:// doi.org/10.1017/S0033291717003294

Author for correspondence:

B. H. Jonsson, E-mail: bo.jonsson@ki.se

\title{
Are older studies lost in database searches for systematic reviews?
}

B. H. Jonsson ${ }^{1}$, R. Winzer ${ }^{2}$ and C. Gornitzki ${ }^{3}$

${ }^{1}$ Department of Clinical Neuroscience, Karolinska Institutet, Stockholm, Sweden; ${ }^{2}$ Department of Public Health Sciences, Karolinska Institutet, Stockholm, Sweden and ${ }^{3}$ University Library, Karolinska Institutet, Stockholm, Sweden

We appreciate that Firth and colleagues undertook writing a systematic review on nutritional interventions for schizophrenia (Firth et al. 2017). Our concern is finding all relevant original studies for a systematic review.

The paper claims electronic searches were made for several databases from inception to July 2016. After identification, screening and assessment for eligibility, 18 studies were included, the oldest from 1990.

As database searches were not restricted to certain years, we notice that some papers published before 1990, which probably fulfilled the authors' criteria were not included. Thus, we are interested if there may be relevant studies not identified in the data extraction process. We find the search words in Supplement 1 highly relevant, but the full search strategy is not described. As the reader is not informed which studies were excluded, providing an extensive search strategy would have facilitated replications of the search.

We found two reviews with a focus comparable with the Firth review. In 1991 a paper (Kleijnen \& Knipschild, 1991) reviewed controlled trials of the vitamins B3 and B6 in mental disorders. For schizophrenia 17 trials in adults, published between 1955 and 1978, were included. Nine studies were described as randomized controlled trials and double-blinded (Hoffer et al. 1957; Hoffer, 1962; Ramsay et al. 1970; Ananth et al. 1972; 1973; McGrath et al. 1972; Altman et al. 1973; Wittenborn et al. 1973; Deutsch et al. 1977). However, one reference (Hoffer, 1962) is a book and may not have been eligible for the Firth review. We are concerned whether the other eight original publications, were excluded or not identified, respectively, in the Firth paper.

In 2011 a systematic review (Smedslund \& Berg, 2011) included 22 studies from 1957 to 2006 with vitamin interventions. Eight of these were the papers referred above from the Kleijnen review. Four studies were not included in the reviews by Firth or Kleijnen. Two of these were indexed in PubMed (Lohr \& Caligiuri, 1996; Vaughan \& McCohagny, 1999), and two were found in Google Scholar (Joshi \& Eswaran, 1980; Lerner \& Miodownik, 2007).

Thus, we found 12 studies included by Smedslund but not by Firth. Inclusion of any of these original studies may or may not have had implications for the main results. However, to be able to draw sound conclusions on the body of evidence, all relevant original studies meeting a review's criteria have to be retrieved and included in a systematic review. Otherwise, results may be incomplete or false.

Even if librarians or information specialists participate in database searching, as recommended (Higgins \& Green, 2008), older studies may not be found for different reasons. Database indexing may be incorrect or non-existent and papers may lack abstract. However, studies should not be discarded because of their age. Systematic reviews are becoming increasingly common, and maintaining a high quality is important.

\section{References}

Altman H, Mehta D, Evenson RC and Sletten IW (1973) Behavioral effects of drug therapy on psychogeriatric inpatients. II. Multivitamin supplement. Journal of the American Geriatrics Society 21, 249-252.

Ananth JV, Ban TA and Lehmann HE (1973) Potentiation of therapeutic effects of nicotinic acid by pyridoxine in chronic schizophrenics. Canadian Psychiatric Association Journal 18, 377-383.

Ananth JV, Vacaflor L, Kekhwa G, Sterlin C and Ban TA (1972) Nicotinic acid in the treatment of newly admitted schizophrenic patients: a placebo-controlled study. International Journal of Clinical Pharmacology and Therapeutics 5, 406-410.

Deutsch M, Ananth JV and Ban TA (1977) Nicotinic acid in the treatment of chronic hospitalized schizophrenic patients: a placebo controlled clinical study. Psychopharmacology Bulletin 13, 21-23.

Firth J, Stubbs B, Sarris J, Rosenbaum S, Teasdale S, Berk M and Yung AR (2017) The effects of vitamin and mineral supplementation on symptoms of schizophrenia: a systematic review and meta-analysis. Psychological Medicine 9, 1515-1527.

Higgins J and Green S (2008) Cochrane Handbook for Systematic Reviews of Interventions. Chichester: Wiley. Hoffer A (1962) Niacin Therapy in Psychiatry. Springfield: Charles C Thomas.

Hoffer A, Osmond H, Callbeck MJ and Kahan I (1957) Treatment of schizophrenia with nicotinic acid and nicotinamide. Journal of Clinical and Experimental Psychopathology 18, 131-158. 
Joshi VG and Eswaran S (1980) Vitamins B1, B6, and B12 in the adjunctive treatment of schizophrenia. Journal of Orthomolecular Psychiatry 9, 35-40.

Kleijnen J and Knipschild P (1991) Niacin and vitamin B6 in mental functioning: a review of controlled trials in humans. Biological Psychiatry 29, 931-941.

Lerner V and Miodownik C (2007) Vitamin B6 - The Experience in Treating Psychotic Symptoms and Psychotropic Drug-Induced Movement Disorders. New York: Nova Science publishers.

Lohr JB and Caligiuri MP (1996) A double-blind placebo-controlled study of vitamin E treatment of tardive dyskinesia. Journal of Clinical Psychiatry 57, 167-173.

McGrath SD, O'Brien PF, Power PJ and Shea JR (1972) Nicotinamide treatment of schizophrenia. Schizophrenia Bulletin 5, 74-76.
Ramsay RA, Ban TA, Lehman HE, Saxena BM and Bennet J (1970) Nicotinic acid as an adjuvant therapy in newly admitted schizophrenic patients. Canadian Medical Association Journal 102, 939-942.

Smedslund G and Berg RC (2011) Effects of Vitamins, Fatty Acids, Minerals, and Other Dietary Supplements on Schizophrenic Symptoms in People with Schizophrenia. Report from Norwegian Knowledge Centre for the Health Services (NOKC) No. 19-2011. Oslo: Norwegian Knowledge Centre for the Health Services.

Vaughan K and McCohagny N (1999) Megavitamin and dietary treatment in schizophrenia: a randomized, controlled trial. Australian and New Zealand Journal of Psychiatry 33, 84-88.

Wittenborn JR, Weber ESP and Brown M (1973) Niacin in the long-term treatment of schizophrenia. Archives of General Psychiatry 28, 308-315. 